\title{
Introduction: Within or Beyond the Paradigm Shift? Teleology and Mechanism in the Early Modern Medical Discourse on the Functions of the Living Body
}

\author{
Roberto Lo Presti
}

The traditional way to account for the great transformations that changed the form, structure, methodologies, aims, conceptions and self-representations of that specific kind of knowledge as well as of intellectual enterprise that we qualify as "scientific" at the rise of the Modern Age can be described in following terms: the "Scientific Revolution" in medicine and biology as well as in all the other sciences would have been characterised, and prompted, by a progressive and radical dismissal of the Aristotelian world picture - a picture based on a teleological conception of the relations between the forces, events, processes and elementary constituents which reality consists in - and accordingly by the forming of a new world picture, alternative and even antagonistic to the old dismissed one. The highest, most rigorous and most consistent expression of this new world picture is to be found in the Cartesian philosophy and its most fundamental theoretical premise in the assumption that every aspect of reality, every macro- or microsystem of causal relations within the real world can be satisfactorily described and accounted for in purely mechanistic terms, therefore without applying any concept of "finality" and "purposiveness" or, more precisely, any category of "final causation" to the whole of the metaphysical as well as of the natural and physical (therefore, also biological and physiological) phenomena and processes. From this "discontinuistic" perspective the development of the modern scientific method as well as of the very idea of "science" as we still conceive it would have been the result of a clear, peremptory and even dramatic paradigm shift. ${ }^{1}$

1 In adopting the notion of "paradigm shift" I am referring of course to Kuhn 1962. Examples of discontinuistic accounts of the formation of "modern" science are Butterfield 1959 and Koyré's 1939, 1957, 1961, 1966.

Roberto Lo Presti, Humboldt-Universität zu Berlin, Institut für Klassische Philologie, Unter den Linden 6, D-10099 Berlin (roberto.lo.presti@hu-berlin.de) 
And it is in the frame of this paradigm shift from a teleological to a mechanistic world picture that one should also look at the process of transformation undergone by the medical knowledge between the half of the $16^{\text {th }}$ century (in 1543 Vesalius published his De humani corporis fabrica) and the first half of the $17^{\text {th }}$ century (in 1628 Harvey published his De motu cordis and in 1662 Descartes' Traité de l'homme first appeared laying the theoretical foundations for what has been called "Iatromechanism"), the same process, which Mirko Grmek once defined as the "first biological revolution" in medicine. ${ }^{2}$

This account of the breakdown of the ancient episteme and the contextual rise of modern "science" is usually paired with another historico-epistemological narrative - as discontinuistic as the former -, whose object are the reaction(s) and the attempts made by a number of philosophers, physiologists and anatomists to qualify, problematize, shade, question and finally dismiss the mechanistic world picture and in particular the mechanistic accounts of the constitution, functions and organisation of the living bodies. The first traces of this anti-mechanistic reaction are to be found already towards the end of the $17^{\text {th }}$ century in authors, who, while formally still professing their allegiance to the mechanistic paradigm, in reality started developing a clear awareness of some insufficiencies and/or inconsistencies of such paradigm with respect to the explanation of life. Anyway, it is in the $18^{\text {th }}$ century that the revival of a teleological approach to the explanation of life and living organisms reached its peak in the intellectual milieu of the medical faculty of Montpellier and found its most extreme expression in the forming of the vitalistic paradigm, as it was developed by Théophile de Bordeu and by his student Paul-Joseph Barthez. It is within this paradigm that notions like "soul" and "ensouled body" "faculty" (or "faculties") and "vital force" provided the conceptual core of a theoretical framework which claimed to be free in every respect from categories of thought, forms of reasoning, schemes of causation, analogical as well as metaphorical apparatuses characteristic of the mechanistic world picture. ${ }^{3}$

The first and most fundamental aim of the contributions collected in this special issue is to put under close scrutiny the theoretical premises, which such a discontinuistic approach to the formation and articulation of the early modern medical and biological discourses is grounded on, and ultimately to raise the question, whether, in which terms and to what extent the dialectics that developed within these discourses between teleological and mechanical

2 Grmek 1990, 8-10 and 115-139 (on the rise of a mechanistic conception of life as cause and expression of this "biological revolution").

3 On Montpellier vitalism see Williams 2003. The contrast, but also the intertwinements, between vitalism and mechanism have been object of investigation of the papers collected in Saad/Cotin 2001. 
models of the living body is to be described not only, not always and not necessarily in terms of dichotomy, opposition, contraposition, reciprocal exclusion, but rather, or at least also, in terms of exchange, inclusion, adaptation, assimilation, hybridization.

By raising this question we have tried to make an historiographical and epistemological move absolutely in line with, and even prompted by, a number of more or less recent studies on the relationship between teleological and mechanistic explanatory models both in ancient natural philosophy and medicine (especially in Aristotle and Galen) and in early modern Aristotelianism, that is to say in those (teleologically-oriented) systems of thought against which the new mechanistic world picture arose in the course of the $17^{\text {th }}$ century.

On the one hand, the investigations on Aristotle's biological treatises carried out in the last decades by J. Lennox, A. Gotthelf, W. Kullmann, H. von Staden, D. Balme, J. Hankinson have shed fresh light and provided new insights on the relatively open and, so to say, defective structure of Aristotle's teleology as well as on the compatibility of teleology and mechanism within Aristotle's theory of causation. ${ }^{4}$ For it has been noted that, especially when it comes to explaining some specific aspects of phenomena and processes related to the biological domain, Aristotle just goes beyond the category of final cause and introduces the notion of "hypothetical necessity", which, while describing a kind of "mechanistic" relation between a necessitating and a necessitated entity, does not infringe on the teleological structure of reality. ${ }^{5}$ As J. Hankinson has brilliantly put it, "appealing to the hypothetical necessity of certain materials is not meant to be an alternative to teleological explanation; rather it is part of it. The required end determines that, in view of their physical properties, only a restricted set of materials can in fact be employed in realizing it; but they do not yet necessitate it."

Even in Galen's theory of causation, which radicalizes the Aristotelian notion of final cause by introducing the idea a purposeful and intentional design of Nature that rules over the whole of the biological and physiological processes, teleological and mechanical, if not mechanistic, explanations do not necessarily exclude each other and in some contexts they even seem to be complementary. This is the case of Galen's account of the relation

4 See Gotthelf 1987, Cooper 1987 and Balme 1987 (all included in the section on "teleology and necessity in nature" in Gotthelf/Lennox 1987), Lennox 2001, especially 225-258, Gotthelf 2012, Kullmann 1974, 269-329 and 1979, Balme 1972, 76-84, Hankinson 1998, Staden 1997.

5 Aristot. Phys. II, 9, 199b33-200a15. Cf. PA I, 1, 639b21-30, 642a1-14, 33-6; GC II, 11, 337b14-338a4.

6 Hankinson 1998, 145. 
between "constitution of the body" and "character of the mind", as Philip van der Eijk has recently shown ${ }^{7}$ by focusing on how Galen repeatedly shifts in his psychological works from a "top-down" account of how Nature has arranged the material constituents of the body in order for this or that cognitive/perceptual function to be fulfilled to "bottom-up" explanations, in which he starts from investigating the material constitution of the individual body and then looks at the emergence of the whole range of its psychological faculties as the very result of that material constitution.

On the other hand, a reassessment of the role played by late Aristotelianism in the European intellectual scenario - and especially in natural philosophy and mechanics - in the $16^{\text {thand }}$ still in the early $17^{\text {th }}$ century has been made possible by a number of studies published in the last few years, among which it is worth mentioning at least Dennis Des Chene's investigations into the late Aristotelian roots of some key-aspects of Descartes' physics $^{8}$ (Des Chene focuses above all on the transformations of the Aristotelian system of natural philosophy prompted by the Coimbra commentaries and on the influence exerted by these commentaries on Descartes' understanding and reception of Aristotle's physics) and Helen Hattab's works on the Renaissance and early modern reception of the Pseudo-Aristotelian Problemata Mechanica. ${ }^{9}$ This text provides in many ways an example of how the reception of ancient theories may have influenced and at the same time been influenced by the elaboration of new theories. For a collection of inquiries addressing some crucial issues of ancient mechanics within a theoretical framework clearly in line with the principles of Aristotle's physics (this proves most evident in the account of the circular movement) became at some point, as result of a deep process of rethinking, a sort of avant la lettre manifesto of the new and entirely mathematized "science of mechanics", as testified by the way in which some key figures of this new science such as Giovan Battista Benedetti, Guido Ubaldo and Galilei understood and commented the Problemata Mechanica and even made use of this text as a source of positive knowledge and as a starting point for further speculations.

If we move to the opposite front, that of the antimechanistic reaction and of the revival of a teleological conception of the life processes, things do not get less complex. For we see that, instead of just being dismissed, the very concept of machina corporis underwent a complex process of transforma-

7 Eijk 2013.

8 Des Chene 1996, 2000 and 2010.

9 Hattab 2004 and 2005. 
tion; the same thing happened with a wide range of mechanistic explanatory and descriptive patterns, which were still active - although in form of analogical or metaphorical reasoning - also in overtly teleological and vitalistic accounts of the bodily functions and faculties. It will suffice to mention one of the most important works of Paul-Joseph Barthez, the Nouvelle Méchanique des mouvements de l'homme et des animaux (1798), to get an idea of the impact that the mechanistic imagery had on the constitution of the medical and biological discourse far beyond the age and the milieus in which mechanism was perceived as the key to a scientific understanding of the world.

This complex scenario provides the background for all the contributions contained in this volume. A characteristic common to all of them is to look at teleology and mechanism as "fluid" conceptual entities and as interdependent explanatory paradigms, which have formed in relation to each other and prevailed one over the other in different times depending on various epistemic and non-epistemic factors, without being able, however, to replace in every respect the antagonistic paradigm and therefore to determine its complete rejection and disappearance. The way in which each paper actualizes this approach very much depends on the specific nature of the texts and issues taken into account.

Fabio Tutrone's paper "The body of the soul. Lucretian echoes in the Renaissance theories on the psychic substance and its organic repartition" sheds fresh light on how teleological and mechanistic, functional and physicalistic conceptions of the soul and its relationship with the body have intertwined in the Renaissance reception of Lucretius, whose poem De rerum natura represented in the Renaissance the first and most essential source of Epicurean philosophy. In the first part of his paper, Tutrone focuses on what he defines the "assimilation of Peripatetic elements in Lucretius' Epicurean account of the soul" and more specifically on the "key link" between Epicurus' and Aristotle's psychological theories. This link, which according to Tutrone is to be found in the interpretation of the body-soul relationship, described by Aristotle in formal/functional terms and by Epicurus in material/functional terms, paved the way to the integration of Epicurean concepts into the physical systems of Renaissance Aristotelian thinkers such as Bernardino Telesio, Agostino Doni and Francis Bacon, whose psychological theories Tutrone takes into account in the second part of his paper.

Guido Giglioni's contribution, "Human, Elephants, Diamonds and Gold: Pattern of Intentional Design in Girolamo Cardano's Natural Philosophy", explores a case of rejection of Aristotle's "intrinsic" teleology within a world view which, however, does not reject teleology as such. In this paper partic- 
ular attention is paid to the way in which Cardano, on the one hand, introduced intentionality as an essential characteristic of the final cause and, on the other, managed to disentangle his "intentional" teleology from any anthropocentric conceptions of reality. In this respect a key distinction is that between an "oblique" teleology - proper to the processes in animate being and the actions ruled by human will, which do not necessarily occur for the sake of an end - and a "noetic" teleology implying the existence and action of what Cardano calls "celestial souls". Interestingly these two ways of manifestation of the teleological structure of reality are subsumed one under the other in Cardano's system, insofar the latter takes for granted that and I now quote from Giglioni's paper - "oblique human teleology is wisely controlled by a higher level of purposive understanding, under the supervision of a cohort of celestial intelligences". Also in Cardano, as in Melanchthon, the shift from "intrinsic" to "extrinsic" teleology is characterised by a new emphasis on the "artificiality" of nature, which has to be taken as evidence of the purposive, intelligent, intentional and deliberate agency of the soul, insofar as, in Cardano's eyes, nature is anything but "the impression that soul has made upon bodies".

The reception and transformation of the Aristotelian teleological paradigm also played a primary role in the early modern medical discourse, especially in relation to the rise of a comparative method of anatomophysiological investigation of the body. This is especially true as far as the medical faculty of the university of Padua is concerned, where eminent Aristotelians such as Fabricius Aquapendente, Cesare Cremonini, Jacopo Zabarella held chairs of medicine and/or of natural philosophy, and where key figures of early modern medicine such as Vesalius and Harvey accomplished their studies. The most meaningful medical discovery of the time that is, the discovery of the blood circulation made by William Harvey is very much an outcome of this intellectual and scientific milieu. Both Peter Distelzweig's and Roberto Lo Presti's papers actually deal with such discovery and with the debate prompted by the publication of Harvey's De motu cordis in 1628. Distelzweig shows that the search for a final cause, which may allow to explain the action of the heart in teleological terms, is the true Leitmotiv and driving force that pervades the whole argumentative structure of the De motu cordis, in full accordance with the general principles of Aristotelian epistemology and theory of causation. In this regards Distelzweig argues that the idea according to which the logic and methodology of Harvey's discovery represented a shift towards the mechanization of the heart is entirely to reject, since Harvey, while actually describing the heart as a pump and while accounting for the movements of the blood in the veins 
and arteries in light of principles taken from hydraulics and from a mathematical method of reasoning, never abandons an overall teleological conception of the physiological processes.

Lo Presti's paper addresses the tension between teleology and mechanism intrinsic to Harvey's discovery from an "excentric" point of view, so to say, since it deals with the criticisms moved to Harvey by Hieronymus Franzosi, an until now almost unknown Aristotelian of the Paduan milieu, who in 1652 published a work entitled De motu cordis et sanguinis in animalibus pro Aristotele et Galeno adversus anatomicos neotericos. Franzosi's point of view is expression of an extremely conservative and dogmatic Aristotelianism and, if considered in itself, has not that much to offer, neither in terms of originality of contents nor in terms of methodological accurateness. Yet, understanding the rationale of Franzosi's criticisms may allow us to better grasp some key aspects of Harvey's theory of the heart functioning, namely those aspects which are more strictly related to Harvey's adoption and adaptation of the Aristotelian teleology. For, while in Aristotle's biology the bodily parts are teleologically accounted for as being organs of an ensouled body, the very notion of soul is not to be found in Harvey's De motu cordis et sanguinis, as Franzosius does not fail to notice and to reproach to Harvey. In this regards, Harvey's theory of the blood circulation may be read as an attempt to combine the teleological explanation of the parts of the living body with a naturalized conception of life and life processes or, to put in other words, as an attempt to provide a post facto reconstruction of a teleology which is meant to explain the role of each organ - thus a kind of explanatory (rather than metaphysical) teleology.

This is exactly what Charles Wolfe argues about Harvey in his paper entitled "Teleomechanism redux? Functional physiology and hybrid models of Life in early modern natural philosophy". Wolfe addresses in a more systematic and explicit way the same issue, which all the contributions included in this special issue deal with to different degrees and from different angles, namely the impossibility of drawing a clear line of demarcation between so called (or self-proclaimed) mechanistic and so called (or self-proclaimed) teleological models of life. A number of examples - the presence of "purposive" or "functional" features in Cartesian physiology, the occurrence of the Galenic teleological notions of "action" and "office" (actio and usum) of the bodily parts in anatomical accounts otherwise labelled as mechanistic, La Mettrie's adoption of the model of the "body-machine" as part of a declaredly anti-mechanistic and anti-reductionist representation of the life processes - provide Wolfe with sufficient evidence to argue for the existence of an hybrid approach to the problem of explaining life, an approach - com- 
mon to a number of different philosophers, anatomists and physiologists like Harvey and Boyle, Fontenelle and Leibniz, the Montpellier vitalists and some of the $18^{\text {th }}$ century materialists - which Wolfe characterises as "teleomechanism" and which he describes as a synthetic capacity, which produces an entirely immanent explanatory model, without levels or ontological differentiations.

The last paper of this volume, Anne-Lise Rey's "Anatomie du corps et de l'esprit chez Francis Glisson", looks at the interplay between mechanistic and teleological models of life and of the living from the perspective of the post-Cartesian psychology and physiology of perception. With Rey's analysis of Glisson's notion of irritability as an internal force of action and reaction, which the fibres are endowed with, we move from the plan of a philosophical physiology of the upper cognitive faculties to that of an anatomo-physiological investigation into what could be defined as a "perception without consciousness" or also as a pre-sensory perception. In pursuing such an ambitious research programme, Glisson combines anatomy of the body and anatomy of the mind, the latter being intended as a dissection, that is an analytical investigation, of the intellectual operations carried out by the human mind. Interestingly, the way in which Glisson distinguishes between sensory perception as a property of the nervous fibres and preconscious and pre-sensory perception as a capacity of action and reaction common to all the living beings is very much in line with, and quite plausibly to a certain extent inspired from, the Galenic distinction between sensation, which is ruled by the soul and depends from the action of the brain and the nervous system, and natural faculties, in virtue of which all the physiological and vegetative activities and processes of the body are explained. It is clear, therefore, why and in what regards Glisson's notion of irritability can be looked at as an attempt to question, and ultimately to reject, the mechanistic account of the activities of the living body. For, while adopting some key categories of the mechanistic representations of the body such as those of "contraction" and "distension", Glisson emphasizes the existence of a selfactualising vital activity, which - being intrinsic to, and characteristic of, the living body - also hints at the purposiveness of processes taking place in it.

Some of the papers contained in this volume have been first delivered at the annual Conference of the Canadian Society of Renaissance Studies (Montreal, May 2010) within the frame of a panel whose subject was "Teleology and Mechanism in Renaissance medicine and natural philosophy". The theme and the aims as well as the epistemological and historiographical approach of this special issue are in many regards expression of, and deeply rooted in, two research programmes, to which both the 
editor and many of the contributors have been attached or with which they have collaborated on a regular basis for the last four years. The first is the ANR-PHILOMED Project La refonte de l'homme: découvertes médicales et anthropologie philosophique (siècles XVII-XVIII) (2009-2013). This research programme was directed by Stefanie Buchenau, Claire Crignon, who has coauthored the thematic bibliographical review for this special issue together with Delphine Antoine-Mahut, and Anne-Lise Rey and counted among his members the editor of this volume and among his collaborators Charles Wolfe and Guido Giglioni. The second is the Alexander von Humboldt Research Programme "Medicine of the Mind, Philosophy of the Body", based at the Humboldt Universität zu Berlin and directed by Philip van der Eijk, within the frame of which the editor of this volume has been carrying out his research activity since September 2010.

\section{Bibliography}

Balme, David M., "Teleology and necessity", in: Allan Gotthelf/James G. Lennox (eds), Philosophical issues in Aristotle's biology (Cambridge 1987) 275-285

Balme, David M., Aristotle's De partibus animalium I and De generatione animalium I, translated with notes (Oxford 1972)

Butterfield, Herbert, The Origins of Modern Science 1300-1800 (New York 1959)

Cooper, John M., "Hypothetical necessity and natural teleology", in: Allan Gotthelf/ James G. Lennox (eds), Philosophical issues in Aristotle's biology (Cambridge 1987) 243-274

Des Chene, Dennis, "Aristotelian natural philosophy: body, cause, nature", in: Janet Broughton/John Carriero (eds), A Companion to Descartes (Blackwell Companions to Philosophy) (Chichester 2010) 17-32

Des Chene, Dennis, Physiologia: Natural Philosophy in Late Aristotelian and Cartesian Thought (Ithaca, NY 1996)

Des Chene, Dennis, Spirits and clocks: machine and organism in Descartes (Ithaca, NY 2000)

Eijk, Philip J. van der, "Galen and the scientific treatise: a case study of Mixtures", in: M. Asper (ed), Writing Science. Medical and Mathematical Authorship in Ancient Greece (Berlin/New York 2013) 145-175

Gotthelf, Allan, "Aristotle's conception of final causality", in: Allan Gotthelf/James G. Lennox (eds), Philosophical issues in Aristotle's biology (Cambridge 1987) 204-242

Gotthelf, Allan, Teleology, first principles and scientific method in Aristotle's biology, Oxford Aristotle Studies (Oxford 2012)

Gotthelf, Allan/James G. Lennox (eds), Philosophical issues in Aristotle's biology (Cambridge 1987)

Grmek, Mirko D., La première révolution biologique: réflexions sur la physiologie et la médecine du XVII siècle (Paris 1990)

Hankinson, Robert J., Cause and explanation in ancient Greek thought (Oxford 1998) 
Hattab, Helen, «Le fondement de la causalité dans les traditions aristotéliciennes et mécanistes», in: Studi Cartesiani II, Atti del Seminario «Descartes et ses adversaires» (Lecce 2004)

Hattab, Helen, "From Mechanics to Mechanism: The Quaestiones Mechanicae and Descartes' Physics", in: Peter R. Anstey and John A. Schuster (eds), The Science of Nature in the Seventeenth Century (Dordrecht 2005) 99-129

Koyré, Alexandre, Études galiléennes (Paris 1939)

Koyré, Alexandre, Du monde clos à l'univers infini (Paris 1957)

Koyré, Alexandre, La Révolution astronomique: Copernic, Kepler, Borelli (Paris 1961)

Koyré, Alexandre, Études d'histoire de la pensée scientifique (Paris 1966)

Kuhn, Thomas S., The Structure of Scientific Revolutions (Chicago 1962)

Kullmann, Wolfgang, Wissenschaft und Methode. Interpretationen zur aristotelischen Theorie der Naturwissenschaft (Berlin 1974)

Kullmann, Wolfgang, Die Teleologie in der aristotelischen Biologie. Aristoteles als Zoologe, Embryologe und Genetiker, Sitzungsberichte der Heidelberger Akademie der Wissenschaften, phil.-hist. Kl. (Heidelberg 1979)

Lennox, James G., Aristotle's philosophy of biology. Studies in the origins of life science (Cambridge 2001)

Saad, Mariana/Jacques Cotin (eds), Mécanisme et vitalisme. Actes du colloque «Vitalisme et mécanisme» organisé par Mariana Saad à la Maison française d'Oxford, 4-5 mai 2001, La Lettre de la Maison française d'Oxford nº 14 (Oxford 2001)

Staden, Heinrich von, "Teleology and mechanism: Aristotelian biology and early Hellenistic medicine", in: Wolfgang Kullmann/Sabine Föllinger (eds), Aristotelische Biologie. Intentionen, Methoden, Ergebnisse. Akten des Symposions über Aristoteles' Biologie vom 24.-28. Juli 1995 in der Werner-Reimers-Stiftung in Bad Homburg (Stuttgart 1997) 183-208

Williams, Elizabeth A., A cultural history of medical vitalism in Enlightenment Montpellier (Aldershot 2003) 